\title{
PROFILE OF VISITORS TO COASTAL AND MARINE TOURISM LOCATIONS IN CAPE TOWN, SOUTH AFRICA
}

\author{
Suveshnee MUNIEN* \\ University of KwaZulu-Natal, School of Agriculture, Earth and Environmental Sciences, College \\ of Agriculture, Engineering and Sciences, Durban, South Africa, e-mail: munien@ukzn.ac.za
}

\section{Amanda GUMEDE}

University of KwaZulu-Natal, School of Agriculture, Earth and Environmental Sciences, College of Agriculture, Engineering and Sciences, Durban, South Africa, e-mail: agumede505@gmail.com

\section{Rivoni GOUNDEN}

University of KwaZulu-Natal, School of Agriculture, Earth and Environmental Sciences, College of Agriculture, Engineering and Sciences, Durban, South Africa, e-mail: rivoni.gounden@gmail.com

\section{Urmilla BOB}

University of KwaZulu-Natal, School of Agriculture, Earth and Environmental Sciences, College of Agriculture, Engineering and Sciences, Durban, South Africa, e-mail: bobu@ukzn.ac.za

\section{Dinolen GOUNDEN}

University of KwaZulu-Natal, School of Agriculture, Earth and Environmental Sciences, College of Agriculture, Engingineering and Sciences, Durban, South Africa, e-mail: dinolengounden@gmail.com

\section{Ntwademela Sanfofa PERRY}

University of KwaZulu-Natal, School of Agriculture, Earth and Environmental Sciences, College of Agriculture, Engineering and Sciences, Durban, South Africa, e-mail: mr.nsperry@gmail.com

Citation: Munien, S., Gumede, A., Gounden, R., Bob U., Gounden, D., Perry, N.S. (2019). PROFILE OF VISITORS TO COASTAL AND MARINE TOURISM LOCATIONS IN CAPE TOWN, SOUTH AFRICA. GeoJournal of Tourism and Geosites, 27(4), 1134-1147. https://doi.org/10.30892/gtg.27402-421

\begin{abstract}
Cape Town, one of South Africa's key coastal tourism destinations, provides a useful case study to examine visitor profiles in Coastal and Marine Tourism (CMT) sites. Nine hundred and seven visitor surveys were completed in purposively selected CMT locations in Cape Town. The main findings reveal that there is diversity among visitors frequenting CMT sites in Cape Town in terms of type of visitor, gender, population group, age, educational level and economic status. Visitors participated in a range of CMT activities and indicated an interest to participate in future activities. Furthermore, high levels of satisfaction with the CMT activities and locations were evident which suggests that a growing demand for CMT activities in Cape Town which needs to be managed. Examining visitor profiles, perceptions, preferences and experiences is important to improve planning and management of these destinations to ensure long-term sustainability.
\end{abstract}

Key words: Coastal and Marine Tourism (CMT), visitor profiles, perceptions, preferences, experiences, Cape Town

\footnotetext{
* Corresponding author
} 


\section{INTRODUCTION}

Bob et al. (2018) argue that Coastal and Marine Tourism (CMT), as part of the oceans economy, offers significant development opportunities that can contribute to job creation and sustainability. The importance of CMT is noted by the United Nations [(UN), 2014] estimates that approximately 350 million jobs worldwide are associated with the oceans, primarily in the fisheries, CMT and research sectors. Furthermore, the United Nations World Tourism Organisation (UNWTO) estimated that of the one billion international tourists recorded in 2012, a third of these tourists visited the seaside (UN, 2014) which reflects that CMT is important in relation to the tourism sector generally and are significant sources of income and foreign exchange earnings in the places and countries in which CMT sites are located. International tourism numbers are further complemented by domestic tourists as well as local visitation to these sites. Rogerson \& Rogerson (2019) note the importance of the blue economy in the South African context, articulated as Operation Phakisa. The potential economic value of ocean resources has garnered attention in other developing contexts as well. For example, Islam \& Shamsuddoha (2018) highlight the potential for blue growth in the context of Bangladesh and Oladele et al. (2018) highlight the potential for coastal tourism in Nigeria. Rogerson \& Rogerson (2019) caution that CMT planning can prioritise attracting investments and economic growth rather than conserving maritime resources. Furthermore, Lithgow et al. (2019) state that the future of coastal tourism is at risk from increasing coastal squeeze as a result of growing demand, environmental degradation and vulnerability to extreme weather events. Similar sentiments are expressed by Rodella et al. (2019) who state that because CMT induces environmental impacts and pressure on the natural resource base; understanding demand and visitor profiles becomes critical for sustainable socio-economic and environmental conservation practices. While there is considerable research that focuses on tourism to seaside or beach destinations generally, few focus on examining the profiles of visitors to CMT locations specifically. Furthermore, research tends to focus on impacts of tourism, focusing primarily on economic considerations (Bob et al., 2018). This study addresses these gaps in the research by examining visitor perceptions of CMT sites that assists to better understand visitor motivations and demands, therefore informing more effective sustainable planning and management of these sites. The next section of the article summarises key issues emanating from a review of selected literature on CMT. This is followed by a brief overview of the case study, Cape Town, which is one of the main coastal tourist destinations in South Africa. Thereafter, the methodological approach adopted is presented. This is followed by a discussion of the key findings in relation to the socio-demographic profiles of the visitors, CMT activities that they participate in and future participation/ interests, and perceptions of CMT locations visited in Cape Town. Finally, concluding remarks are provided.

\section{CMT RESEARCH}

Honey \& Krantz (2007) assert that CMT dates back to the late nineteenth century when wealthy Americans visited coastal areas and is one of largest and oldest sectors of the tourism industry. Nulty et al. (2007, p. 1) define marine tourism as "the sector of the tourism industry that is based on tourists and visitors taking part in active and passive leisure and holidays pursuits or journeys on (or in) coastal waters, their shorelines and their immediate hinterlands". The Mediterranean Maritime Integrated Projects (2014, p. 1) differentiate between coastal and marine aspects as:

Coastal tourism refers to land-based tourism activities including swimming, surfing, sunbathing and other coastal recreation activities taking place on the coast for which the proximity to the sea is a condition including also their respective 
Suveshnee MUNIEN, Amanda GUMEDE, Rivoni GOUDEN, Urmilla BOB, Dinolen GOUDEN, Ntwademela Sanfofa PERRY

services. Maritime tourism refers to sea-based activities such as boating, yachting, cruising, nautical sports as well as their land-based services and infrastructures.

The UN (2014) at the UN Conference on Trade and Development (UNCTAD) held in 2014, identified CMT as one of the main sectors contributing towards the development of the oceans economy (also referred to as the blue economy) which they state offers substantial development opportunities for sectors such as CMT, fisheries and aquaculture, renewable marine energy, marine bio-prospecting and maritime transport given that twothirds of the planet's surface is water. Brouwer et al. (2017) assert that CMT and leisure activities are viewed to have substantial economic, social and recreational value globally.

The United Nations Environment Programme (UNEP, 2009, p. 10) delineates coastal tourism as being "based on a unique resource combination at the interface of land and sea offering amenities such as water, beaches, scenic beauty, rich terrestrial and marine biodiversity, diversified cultural and historic heritage, healthy food and good infrastructure". On the other hand, marine tourism is deemed to include "a number of different aspects such as marine/ coastal environments, marine protected areas and marine activities which together contribute to its existence" (Seymour, 2012, p. 27). There is a wide variety of coastal and marine related leisure and recreation activities.

The National Department of Tourism [(NDT), 2016] differentiates between coastal tourism and marine tourism activities. Specifically, they note that coastal tourism includes activities such as coastal wildlife tourism which involves land-based viewing of wildlife, sand/ beach activities (shoreline/ beach bathing, sun-bathing, picnicking, fishing on the beach, walking and horse riding along the shoreline, sand sculpting, sand dune surfing, beach volleyball and soccer, etc.), coastal heritage and events (local seafood and cultural tourism), sightseeing (lighthouse tourism, cycling and running along the shore, etc.), educational and scientific excursions including visiting aquariums, spiritual experiences and pure recreational (dining or shopping at beach locations) activities. Marine tourism activities include water-based marine wildlife tourism (seal, dolphin, turtle and whale watching from a boat), boat-based recreational and competitive fishing, scuba diving/ snorkelling, water sports (surfing, yachting/ sailing, water skiing, etc.), ocean experiences (cruise tourism, island tourism, under water archaeology, etc.) and events on water.

The importance of the oceans economy is underscored in the South African context which has a coastline of $3000 \mathrm{~km}$ (Saayman \& Saayman, 2017; Seymour, 2012). Lucrezi et al. (2018) state that South Africa's long coastline is dominated by sandy beaches, many of which are valued and exploited for recreation and tourism. Specifically, Lucrezi et al. (2016, p. 1) state that "sandy beaches are invaluable ecosystems, offering services that are critical for the survival of coastal communities, and possessing intrinsic values that need to be protected”. The Department of Planning, Monitoring and Evaluation (DPME, 2015, p. 4) articulates Operation Phakisa's vision in the South Africa context: "by 2030 South Africa is the premier experience-based CMT destination in Africa and is renowned as a top CMT destination globally with a unique range of experiences for all visitors". The DPME (2014) further indicates that by the year 2033, South Africa's oceans are capable of generating an estimated R129 177 billion to the Gross Domestic Product (GDP) and the current 250000 jobs associated with the oceans economy can be upscaled to 1 million through the efforts of Operation Phakisa. Operation Phakisa's six focus areas are similar to those identified by UNCTAD: CMT, aquaculture, maritime transport and manufacturing, offshore oil and gas exploration, small harbours and marine protection services and ocean governance.

Shelembe (2015) states that the CMT component is championed by the NDT whose responsibility is to initiate projects and interventions in CMT spaces to catalyse job creation and the improvement of lives in these areas, especially among historically disadvantaged 
groups. Operation Phakisa (2014, p. 6) is aimed at implementing "an overarching, integrated ocean governance framework for sustainable growth of the ocean economy that will maximise socio-economic benefits while ensuring adequate ocean environmental protection". Several challenges are identified in relation to CMT by DPME (2014; 2015), Maritime Cluster (2015) and Shelembe (2015). These include maintaining the quality of the natural resource base; insufficient infrastructure and services in CMT locations; lack of uptake of coastal and marine assets/ resources for tourism purposes; limited CMT products and insufficient tourism products in the right place to make South Africa a CMT destination for local, domestic and foreign tourists; high levels of unemployment and unskilled human resources in CMT locations, especially in rural areas; limited participation of the private sector who are generally hesitant to develop tourism products without certainty of profitability; numerous public sector role players, each with different (sometimes conflicting) mandates in respect of CMT development; and underdeveloped and uncoordinated CMT events and recreational activities.

There is considerable and growing research on the impacts of CMT, with a focus on economic impacts specifically. These economic studies reveal the contribution of CMT to economic development. For example, Onofri \& Nunes (2013) model tourists' behaviour using coastal tourism flows (international and domestic coastal arrivals) and tourists' market expenditures from UNWTO datasets. They identified two tourist demand segments: international tourists being influenced strongly by preferences for the cultural and natural environments while domestic tourists chose locations primarily based on beach characteristics. The New Zealand Tourism Research Institute (2009) used a mixed method approach (interviews and online surveys) to examine impacts associated with CMT on visitors, businesses and community. They found that there was a significant daily impact on the local economy with local businesses depending largely on visitors to CMT locations (especially those with interests in diving). They also note the importance of seasonal impacts. Understanding the profile of visitors is also important from an economic perspective since visitor expenditure, especially among tourists, is influenced by satisfaction with and perceptions of a destination which affects revisitation and positive favourable word-of-mouth marketing which is extremely important in the age of social media with visitors sharing their views and concerns globally.

Many CMT studies also tend to focus on specific CMT products/ activities (Bob et al., 2018; Brouwer et al., 2017; Mitra et al., 2019; Myeza et al., 2010; Tkaczynski \& Rundle-Thiele, 2018; Trave et al., 2017). For example, Vianna et al. (2012) examined shark diving tourism in Palau, Phillipines. They found that this activity was a major contributor to the economy, making up approximately 8\% of the GDP. O'Malley et al. (2013) assessed direct expenditures on manta ray dives in 23 countries, estimating that the direct economic impact of manta ray watching tourism was estimated at US $\$ 140$ million annually. Hoyt's (2001) study focused on whale watching and highlighted the commercial as well as the educational, environmental, scientific and socio-economic benefits of this activity and estimated it to be a US $\$ 1$ billion industry globally with more than 9 million visitors travelling to 87 countries. Tkaczynski \& Rundle-Thiele (2018) investigated whale watching tourist differences using segmentation to understand who has the highest return on investment and who yields the highest dividends.

The importance of examining segmentation of tourist demands at coastal and marine destinations is also noted by Carvache-Franco et al. (2019) in their study in Ecuador. O'Connor et al. (2009) examined boat and land-based whale watching in South Africa, noting a slight increase (of $1.1 \%$ per annum) in overall numbers of whale watching tourists from 1998 to 2008. They found, however, that over the same period boat-based 
Suveshnee MUNIEN, Amanda GUMEDE, Rivoni GOUDEN, Urmilla BOB, Dinolen GOUDEN, Ntwademela Sanfofa PERRY

whale watching increased substantially at a rate of $14 \%$ per annum. They also indicated that whale watching is a major tourist attraction in Western Cape (including Cape Town which is the study site for this research). Orams \& Lück (2014) also focused on whale watching, using Tonga as a case study. They noted the economic benefits to the local economy and that the numbers of visitors are increasing annually, which is a similar trend to that in South Africa. The importance of whale watching is also emphasised by Higham et al. (2016) who indicate that whale watching is one of the fastest growing components of the tourism industry worldwide, gaining considerable support from the international community as a non-consumptive activity of marine species. Other studies in South Africa included Myeza et al.'s (2010) investigation of the socio-economic impacts for local communities of the sardine run along KwaZulu-Natal's coastline. Gallagher \& Hammerschlag (2011) examined the socio-economic impacts of shark-ecotourism focusing on Apex Expeditions which is a tour operator in the Western Cape. In the South African context, Statistics South Africa (2015) indicates that in 2015 98.3\% of foreign arrivals into the country were for holiday purposes and that the number of domestic tourists in South Africa is increasing annually with 11.2 million domestic travellers recorded in 2011. The main tourist motivations identified by Statistics South Africa (2015) are visiting friends and family as well as leisure/ holiday purposes with a major attraction for visitors being beach destinations. CMT, according to Bob et al. (2018), has become a significant factor in the economy and a great tool for job creation. Research also shows that the economic value of CMT provides an important incentive for the conservation of coastal and marine-based natural resources (Biggs et al., 2015; Orams \& Lück, 2014).

Examining the profiles of beach/ seaside visitors is important to understand who visits CMT locations, what their interests are as well as perceptions and experiences to improve planning and management of these destinations to ensure long-term sustainability (Atzori et al., 2018; Chen \& Teng, 2016; Han et al., 2018; Martinis et al., 2019). Atzori et al. (2018) reveal that perceptions of beach comfort influence destination choice and future travel preferences. Furthermore, Jarvis et al. (2016) indicate that socioeconomic and environmental variables influence trip satisfaction and the prospect of visitors returning. They add that it is not only the destination itself and CMT stakeholders (such as CMT business and tour operators) that influence trip satisfaction but also the service sector generally (such as safety and security as well as water and electricity provision) that should be considered. Chen \& Teng (2016) and Han et al. (2018) note the importance understanding perceptions and perspectives of CMT locations which contributes to acceptable, practical sustainable management policies and practice.

They also highlight considering carrying capacity which is particularly relevant in environmentally vulnerable and sensitive beach tourism locations such as Boulders Beach in Cape Town which is home to a penguin colony. Han et al. (2018) specifically state that carrying capacity is also important in urban beach contexts (such as Cape Town) to protect environmental resources and promote green development. Hung \& Petrick (2011) indicate that to better understand and manage South Africa's CMT assets, it is crucial to know the market that uses them, the reasons why people travel and what the visitors would like to gain from their trip. Similar sentiments are expressed by Orams \& Page (2000) who indicate that examining visitor profiles (especially understanding tourists, who they are and what their attitudes, beliefs and desires are) is an important aspects of tourism research. Lucrezi et al.'s (2018) study of beachgoers in South Africa revealed that the profile and perceptions of beachgoers differed in relation to the level of urbanisation and geographic location of the beaches. They assert that this differentiation needs to be considered when managing recreational activities on sandy beaches. Saayman \& Saayman 
(2017) examine whether the Blue Flag status of beaches attracts a different type of beachgoers in the Western Cape. They found that the most important beach-specific attributes that attract beachgoers were beach cleanliness and infrastructure.

The above discussion reveals the importance of CMT to the tourism sector generally and to economic development. Additionally, the social benefits in relation to promoting leisure activities and entertainment are also evident. Furthermore, environmental benefits associated mainly with educational opportunities and promoting responsible behaviour are underscored. However, overuse and unsustainable practices such as littering, development of infrastructure and services, and degrading or depleting biodiversity (for example, over-fishing or not adhering to regulations about the amount of fish to catch or when to fish) can have detrimental consequences that can ultimately undermine the natural resource base that CMT thrives on. Lui et al. (2019) indicate that the global increase in CMT has resulted in increased development in many major beach locations. Furthermore, Biggs et al. (2015) warn that CMT is being threatened by climate change. Additionally, Joseph (2017) raises concerns that there are considerable pressures on CMT locations and environments given that these areas are home to $50 \%$ of the world's population and increasing numbers of beach visitors. This is supported by Lucrezi et al. (2018) who assert that while sandy beaches provide ecosystem services which are increasingly recognised and valued globally, they remain under threat from the overexploitation and degradation of these services, mostly attributable to human pressures. Oh et al. (2010) argue that it is important to balance local and tourist demands and expectations on coastal and marine resources which are increasing. In this context, understanding visitor profiles will assist in improved planning and management of CMT spaces and resources. Furthermore, as indicated by Lucrezi et al. (2018) examining visitor profiles contributes to understanding diversity (from social to environmental) which can result in better management and marketing interventions and strategies.

In the South African context (and this is the case globally as well), there is limited research that focuses on examining CMT visitor profiles. This study specifically has a screening question to ensure that only persons in the selected CMT locations were interviewed who were visiting the area specifically to participate in CMT activities. Thus, this study contributes to better understand CMT visitors specifically.

\section{MATERIALS AND METHODS}

\section{Cape Town as a case study}

Cape Town (and the Western Cape province more generally where Cape Town is the main city) is regarded as South Africa's key international tourist destination and is among the top three in relation to domestic tourism. Frey \& George (2010) specifically state that Cape Town is an internationally acclaimed top tourist destination globally. Hattingh \& Swart (2016) note Cape Town's rich heritage and cultural diversity as well as unspoiled natural resources including beach and mountain environments. CMT is central for regional economic growth and job creation with major tourism sites such as Table Mountain and Robben Island (both United Nations Educational, Scientific and Cultural Organisation World heritage sites) being associated with CMT related activities. Additionally, Cape Town has several beach and port tourist locations such as the V\&A Waterfront, Boulders Beach (where one can swim with penguins), Camps Bay, etc. These destinations are prime areas frequented by both locals and persons from outside the city.

\section{Method employed for data collection}

The survey data used for this study was collected as part of a larger study supported by the NDT to develop a framework to assess the economic impacts of CMT in South 
Suveshnee MUNIEN, Amanda GUMEDE, Rivoni GOUDEN, Urmilla BOB, Dinolen GOUDEN, Ntwademela Sanfofa PERRY

Africa. Survey-based data using a structured questionnaire from CMT site visitors was collected in Cape Town from purposively selected locations which are known to be key CMT locations including the V\&A Waterfront and sandy beaches along its coastline since, as indicated by Lucrezi et al. (2018) and Lucrezi \& van der Walt (2016), sandy beaches are the main attractions for visitors or beachgoers in South Africa. A quantitative survey design was used. The survey included questions on the socio-demographic and residential locational profiles of the visitors, the main CMT products/ activities consumed during the visit when the interview was conducted as well as future interest in CMT products/ activities, and perceptions of experiences and CMT locations visited. Face-to-face interviews were conducted with trained fieldworkers in the selected locations. This data is analysed thematically. In the selected CMT locations in Cape Town, 907 face-to-face visitor surveys were completed during September 2018 to January 2019 using a spatiallybased, systematic sampling approach. Research was undertaken in purposively selected CMT sites along Cape Town's coastline. At the selected CMT locations, a spatially-based sampling approach was adopted whereby fieldworkers at the selected locations were trained to complete the surveys at specific places and during specific days. On the selected day and at the specific CMT location, the first person interviewed was purposively selected by the fieldworker. To limit bias in respondent selection, thereafter, adult persons were selected systematically. Specifically, on completion of a survey the $20^{\text {th }}$ person passing by was approached to participate. If the selected person declined to participate or did not meet the requirements as per the screening question that they should be in the location specifically to participate in CMT activities, the next person passing by was approached.

This approach is often used to reduce bias since beachgoers and persons visiting CMT sites (as the targeted population groups) are not known to permit random sampling and this group is constantly mobile. Fieldwork was conducted during peak/ vacation and off-peak periods with a proportionate sampling approach being adopted to ensure that more surveys (650) were completed during peak periods. As indicated earlier, only persons visiting the location to participate in or those who had participated in CMT activities were interviewed. Once data was collected, it was inputted into the Statistical Package for the Social Sciences (SPSS). Frequency Tables were generated and the relevant information in relation to the key themes of this study are discussed.

\section{RESULTS DISCUSSIONS}

\section{Socio-demographic profile of CMT site visitors in Cape Town}

The average age of the respondents was 39.2 years and ranged from 19 to 78 years. Most respondents were in the age categories of $21-30$ (20.1\%), 31-40 (28.1\%), 41-50 (26.1\%) and 51-60 (15.8) years old. These categories made up 90.1\% of the persons interviewed.

It was further noted that most respondents (84.8\%) travelled in groups that spent money together with an average group size of 1.7 , ranging from none to 13 persons. Forty percent of the respondents were accompanied by one other person while $34.6 \%$ were accompanied by 2-3 persons. It was observed during the research that the actual group size of persons travelling CMT locations were much larger but individuals spent money either on themselves or immediate family or partners. The results show that younger and middle aged groups frequented the CMT areas were the interviews were conducted. Almost equal proportions of males (51.9\%) and females (48.1\%) were interviewed. In relation to the educational level of the respondents, the majority of the respondents had some form of post matric qualifications: undergraduate degrees (43.3\%), postgraduate degrees $(30.2 \%)$ and certificates/ diplomas (13\%). Additionally, $9.9 \%$ of the respondents had completed secondary schooling. The average monthly income of the respondents who provided a 
response was $\mathrm{R}_{32} 887.76$ and ranged from none to $\mathrm{R}_{325}$ ooo. Most respondents earned R2O ooo to R5O ooo (42.3\%). A substantial proportion (28.4\%) did not disclose their income stating that this information was confidential. Crosstabulations revealed that tourists and day visitors had higher educational and income levels than local residents which are reflective of the profiles of persons who travel. In terms of the historical population group of respondents, the majority were White (21.6\%) followed by Africans (20.8\%), Coloureds (12.6\%) and Indians (1.4\%). A substantial proportion of the respondents (44.1\%) who were mainly foreigners did not disclose this information.

The results do reflect demographic diversity in relation to who visits CMT locations. However, the disproportionate number of Whites in relation to the demographic profile of Cape Town is evident. Whites earn substantially more than other groups and this may be a reason why CMT locations are frequented by this group. In terms of the socio-demographic profile, the results indicate that CMT sites are visited by diverse groups of persons which affirms Lucrezi et al.'s (2018) findings in relation to beachgoer diversity in South Africa. Table 1 shows that more than half of the respondents (58.5\%) were overnight visitors followed by local residents (21.3\%) and day-trippers (19.6\%). As indicated earlier, there was a screening question to establish whether the respondent participated or will participate in any CMT activity at the location where the interview was being held. The interview continued only if the response was in the affirmative. This was to ensure that the study focused on CMT users/ customers only. A record was kept of the number of persons who responded in the negative, that is, there were in a beach location but did or would not participate in any CMT activity. In this regard, a total of 250 persons were noted. Given that the total number of persons interviewed was 907 , this indicates that $72.4 \%$ of the visitors to the CMT sites were interested in or visited the area because of CMT products or activities.

Table 1. If overnight visitor, day-tripper or local resident ( $\mathrm{n}=907)$

\begin{tabular}{|l|c|c|}
\hline & Frequency & Percentage \\
\hline Overnight & 531 & 58.5 \\
\hline Day-tripper & 178 & 19.6 \\
\hline Local resident & 193 & 21.3 \\
\hline
\end{tabular}

Among the respondents who were overnight visitors and day trippers, most were foreigners (55.8\%) and 23\% were South Africans. This affirms Frey \& George's (2010) claim that Cape Town is a key international tourist destination. In terms of the foreign visitors, most were from the United States of America as well as different countries in Europe (especially Germany, France, Italy, the Netherlands, Spain and United Kingdom) and Africa (especially South Africa's neighbouring countries). These countries are South Africa's (and Cape Town's) key international tourist markets. Domestic visitors were primarily from Gauteng (6.2\%), the Western Cape (6.4\%) and KwaZulu-Natal (5.3\%). Gauteng is the main domestic tourism market in South Africa for beach tourism. The results indicate that CMT activities and environments are key attractions in Cape Town as articulated by Hattingh \& Swart (2016), Hung \& Petrick (2011), Lucrezi et al. (2018) and O'Connor et al. (2009). In the context of Cape Town, the results reveal that key consumers of CMT products and locations were overnight or day-trippers which reinforce Frey \& George's (2010) assertion that Cape Town is a key tourism destination which reveals CMT's contribution to local economic development and tourism destination branding and marketing.

\section{CMT activities participated in and future interest}

Respondents indicated that they participated in several CMT activities during their visit to the beach location where the interview was undertaken. The main activities 
Suveshnee MUNIEN, Amanda GUMEDE, Rivoni GOUDEN, Urmilla BOB, Dinolen GOUDEN, Ntwademela Sanfofa PERRY

shown in Table 2 that respondents participated or planned to participate in were sand/ beach recreational activities (69.9\% participated in and 56.4\% planned to participate), sightseeing (42.8\% participated in and $35.4 \%$ planned to participate), water sports (26\% participated in and $24.7 \%$ planned to participate), coastal heritage activities $(22.5 \%$ participated in and $26.8 \%$ planned to participate) and pure recreational activities (18.6\% participated in and $15.5 \%$ planned to participate). Other key activities respondents participated in that had less than ten percent responses were educational and scientific excursions, events, spiritual experiences, wildlife tourism, recreational fishing, ocean experiences, wildlife tourism and scuba diving/ snorkelling. Most respondents identified more than one activity that they participated in which suggests that CMT activities tend to complement each other. Furthermore, in terms of coastal tourism and marine tourism activities designated by NDT (2016), there is clearly a prominence of coastal rather than marine tourism activities that visitors participated in. This could be as a result of the interviews being conducted on beaches or CMT sites such as the V\&A Waterfront. However, most coastal activities do not require additional payments unlike marine tourism activities where payments are required to participate in these.

Table 2. Types of CMT activities have or will respondent be participating in during visit to beach location (including activities participated in on day of interview) as well as other types of CMT activities

interested in participating in in the future ( $\mathrm{n}=907$, in \% - yes responses only): Multiple responses

\begin{tabular}{|l|c|c|c|}
\hline & THIS VISIT & FUTURE \\
\hline & Did & $\begin{array}{c}\text { Will } \\
\text { do }\end{array}$ & $\begin{array}{c}\text { Future } \\
\text { interest }\end{array}$ \\
\hline Wildlife tourism (e.g. whale watching, turtle tours, seals, dolphins) & 1.8 & 1.9 & 14.1 \\
\hline $\begin{array}{l}\text { Recreational fishing (e.g. boat-based fishing, spear fishing, } \\
\text { fishing competitions) }\end{array}$ & 5.2 & 11.8 & 30.6 \\
\hline Scuba diving/snorkelling (e.g. shark cage diving) & 1.1 & .8 & 10.9 \\
\hline $\begin{array}{l}\text { Water sports (e.g. big wave surfing, kite surfing, stand up paddle } \\
\text { boarding (SUP), yachting, water skiing, water surfing) }\end{array}$ & 26.0 & 24.7 & 53.3 \\
\hline $\begin{array}{l}\text { Ocean experience (e.g. cruise tourism, marinas, island tourism, } \\
\text { shipwreck diving) }\end{array}$ & 2.6 & 3.6 & 25.0 \\
\hline $\begin{array}{l}\text { Events (e.g. marine festivals and marine competitions such as } \\
\text { yacht races or regattas, fishing competitions) }\end{array}$ & 5.7 & 5.2 & 33.0 \\
\hline $\begin{array}{l}\text { Sand/beach recreational activities (e.g. swimming, walking or } \\
\text { running, kite-flying, beach combing, sand dune surfing) }\end{array}$ & 69.9 & 56.4 & 78.2 \\
\hline $\begin{array}{l}\text { Coastal heritage activities (e.g. local seafood and cultural tourism, } \\
\text { cultural history) }\end{array}$ & 22.5 & 26.8 & 46.0 \\
\hline Sightseeing (e.g. light house tourism, cycling, marathons) & 42.8 & 35.4 & 59.5 \\
\hline Educational and scientific excursions (e.g. aquariums) & 7.8 & 9.6 & 36.6 \\
\hline Spiritual experiences & 5.7 & 7.7 & 32.5 \\
\hline Pure recreational (e,g., dining out, shopping) & 18.6 & 13.5 & 34.6 \\
\hline
\end{tabular}

The average number of times that respondents previously participated in CMT activity/ activities in South Africa was 6 times and ranged from none to 365 times. Slightly more than a third of the respondents (36.3\%) indicated none. These were mainly tourists. Among the rest, most of the respondents (48.5\%) indicated between 1-5 times and for $16.5 \%$ this was the first time they participated in a CMT activity in South Africa. The results indicate that CMT locations in Cape Town attract repeat visitors as well as new visitors. Almost all the respondents (98.9\%) indicated that they would participate in similar CMT activities again in South Africa. This suggests high levels of satisfaction among visitors with CMT activities and experiences in Cape Town. High levels of 
satisfaction were also established in relation to responses regarding whether respondents would advise friends, relatives or colleagues to participate in CMT activities in Cape Town. Eighty nine percent of the respondents indicated that they would advise friends, relatives or colleagues to participate and a further $8.3 \%$ stated that they would possibly advise friends, relatives or colleagues. Only 1.2\% stated that they would not and $0.3 \%$ did not respond. Among the 10 respondents who indicated that they would not participate in CMT activities again in South Africa, the main reasons forwarded were unfriendly staff, overcrowding, issues pertaining to safety and security, and locations not being well maintained (specifically dirt and litter were noted). A few respondents did have negative experiences that influence future visitation which is similar to the assertions made by Atzori et al. (2018), Chen \& Teng (2016), Han et al. (2018) and Martinis et al. (2019).

It is interesting to note that substantially more respondents for all activities listed also stated that they would be interested in participating in these CMT activities although they did not participate in the activities during the visit when the interview was held (Table 2). The future interest is also in higher for marine activities.

The survey did not probe why respondents did not participate in a CMT activity during the visit to the location when the interview was held. Future research should examine this aspect to establish reasons (such as the location visited not having the specific CMT activity, costs of participation, inadequate time during visit and lack of knowledge about the CMT activity which they were exposed to during the visit). The results reveal high levels of past, current and future interest in CMT products/ activities which denotes an increase in demand. This needs to be effectively managed as outlined by Atzori et al. (2018), Chen \& Teng (2016), Han et al. (2018) and Martinis et al. (2019) to ensure long-term sustainability. The Table 3 below shows the main activities respondents participated or planned to participate in during their visit to the location other than CMT activities as indicated in the Table 2 above. A range of activities were identified with the main ones being adventure (63\%), food and wine (37.9\%), culture/ heritage tourism (30.5\%), business (22.8\%), shopping (19.8\%), social/ visiting friends and relatives (16\%) and sport (12.1\%). The results closely correlate with known activities and attractions in Cape Town. To make a CMT destination more attractive it is important to cater for broader interests than activities that are directly linked to coastal and marine resources.

The results reveal a wide range of interests among CMT visitors. However, it is important that developments to accommodate these demands do not undermine the integrity and quality of the CMT resource base as underscored by Biggs et al. (2015), Chen \& Teng (2016), Han et al. (2018), Lucrezi et al. (2018) and Lui et al. (2019). The majority of the respondents stated that their primary reason for visiting the CMT location where the interview was held as shown in Table 4 was participation in the CMT activity in the beach/ coastal location (40.4\%) or holidays (29.2\%). Respondents also identified business (15.9\%) and visiting friends and relatives (10.5\%) as the primary reason for visiting the location.

Three respondents stated shopping. A few (3.7\%) provided other responses which included educational, cultural and spiritual reasons. The prominence of recreational and leisure activities (which CMT contributes to) is evident in the responses presented in Table 4. This suggests that these are the main reasons why people visit CMT locations and that these environments need to be protected and maintained for future use.

\section{Perceptions and experiences}

Respondents were asked to rate their experience with various elements of the CMT location where they were interviewed as depicted in Table 5. The responses resonate with the satisfaction with the CMT experiences as noted earlier. A substantial majority of the respondents agreed or strongly agreed with all statements. 
Suveshnee MUNIEN, Amanda GUMEDE, Rivoni GOUDEN, Urmilla BOB, Dinolen GOUDEN, Ntwademela Sanfofa PERRY

Table 3. Main activities respondent intends participating in/ have participated in during visit to location other than coastal and marine activities ( $n=907-$ yes responses only): Multiple responses

\begin{tabular}{|l|c|c|}
\hline & Frequency & Percentage \\
\hline Shopping & 180 & 19.8 \\
\hline Business & 207 & 22.8 \\
\hline Adventure & 571 & 63.0 \\
\hline Medical/ health & 7 & .8 \\
\hline Nightlife & 80 & 8.8 \\
\hline Sport & 110 & 12.1 \\
\hline Visited a casino & 32 & 3.5 \\
\hline Social (visiting friends and relatives) & 145 & 16.0 \\
\hline Food and wine & 344 & 37.9 \\
\hline Theme parks & 54 & 6.0 \\
\hline Cultural/ heritage & 277 & 30.5 \\
\hline Conference & 28 & 3.1 \\
\hline Shows performances & 7 & .8 \\
\hline Visiting natural attractions/ wildlife that were not coastal/ marine & 48 & 5.3 \\
\hline
\end{tabular}

Table 4. Primary/ main reason for visiting location where the coastal or marine activity respondent is participating in is taking place $(n=907)$

\begin{tabular}{|l|c|c|}
\hline & Frequency & Percentage \\
\hline Participation in CMT activity in this beach/ coastal location & 366 & 40.4 \\
\hline Holiday & 265 & 29.2 \\
\hline Business & 144 & 15.9 \\
\hline Visiting friends and relatives & 95 & 10.5 \\
\hline Shopping & 3 & .3 \\
\hline Other (including educational, cultural and spiritual) & 34 & 3.7 \\
\hline
\end{tabular}

Table 5. Level of agreement with specific statements about coastal and marine location (not town/ city as a whole) ( $\mathrm{n}=907$, in \% - yes responses only)

\begin{tabular}{|l|c|c|c|c|c|c|c|}
\hline \multicolumn{1}{|c|}{ STATEMENT } & $\mathbf{N R}$ & $\mathbf{1}$ & $\mathbf{2}$ & $\mathbf{3}$ & $\mathbf{4}$ & $\mathbf{5}$ & Average \\
\hline Well maintained location & - & 1.7 & 2.1 & 7.9 & 34.0 & 54.4 & $\mathbf{4 . 4}$ \\
\hline Parking is adequate & .1 & 9.3 & 6.2 & 13.7 & 42.2 & 28.6 & $\mathbf{3 . 8}$ \\
\hline Sufficient facilities and amenities (e.g. toilets) & - & 5.9 & 4.1 & 15.8 & 31.4 & 42.9 & $\mathbf{4}$ \\
\hline Good refreshment areas/ food variety & - & 4.0 & 3.7 & 12.5 & 39.7 & 40.2 & $\mathbf{4 . 1}$ \\
\hline $\begin{array}{l}\text { This is a green location that encourages responsible } \\
\text { environmental practices (e.g. recycling) }\end{array}$ & .1 & 1.4 & 3.9 & 21.6 & 36.4 & 36.5 & $\mathbf{4}$ \\
\hline Signage to location was clear & - & 1.1 & 4.1 & 14.4 & 39.4 & 41.0 & $\mathbf{4 . 2}$ \\
\hline Safe location & .1 & 2.1 & 2.3 & 15.1 & 36.4 & 43.9 & $\mathbf{4 . 2}$ \\
\hline Entertainment opportunities available in the location & - & 4.3 & 8.4 & 14.8 & 32.3 & 40.2 & $\mathbf{4}$ \\
\hline
\end{tabular}

The highest agreement was for the location is well maintained $(88.4 \%$ with an average rating of 4.4) which was followed by signage to the location was clear $(80.4 \%$ with an average rating of 4.2) and safe location (80.3\% with an average rating of 4.2). Good refreshment areas/ food variety (79.9\% with an average rating of 4.1 ) was rated next followed by sufficient facilities and amenities (74.3\% with an average rating of 4 ) and this is a green location that encourages responsible environmental practices $(72.9 \%$ with an average rating of 4). Entertainment opportunities available in the location $(72.5 \%$ with an average rating of 4 ) and parking is adequate (70.6\% with an average rating of 3.8 ) had the lowest ratings. The results reveal high levels of satisfaction with CMT locations among visitors. This bodes well for CMT in Cape Town since it reveals that there is demand for 
CMT activities which can contribute to economic growth. It also reinforces assertions by Frey \& George (2010) and Hattingh \& Swart (2016) that Cape Twon is one of South Africa's key CMT destinations. The positive perceptions also are likely to encourage repeat visitation and word of mouth marketing as noted by Atzori et al. (2018) and Martinis et al. (2019).

\section{CONCLUSION}

Increasingly research indicates the importance of CMT for socio-economic development and environmental conservation. This study examined CMT visitor profiles, preferences, perceptions and experiences in Cape Town which is important for improved destination planning and management. Better understanding of visitor profiles will also contribute to enhanced segmentation and marketing of CMT products as indicated by Carvache-Franco et al. (2019) since visitor experiences will influence repeat visitation and provide information on target markets. This study specifically underscores the importance of understanding visitor profiles, perceptions and experiences which is a neglected areas of research since CMT research tends to be focused on specific segments and economic impacts as highlighted. Improved understanding of visitor motivations, demands, experiences and perceptions will inform more effective sustainable planning and management of these sites. The results specifically reveal the value that visitors attach to natural resources and experiences in CMT locations which foregrounds the importance of ensuring that the environmental integrity of these sites are maintained.

Thus, economic aspects of CMT cannot be examined in isolation of environmental aspects. In terms of visitor profiles, diversity in relation to a range of aspects are noted which reveal the importance of differing planning, management and marketing strategies to ensure the maintenance and sustainability of CMT resources and locations in Cape Town. Cape Town's CMT locations attract persons and groups of different ages, genders, educational levels and income groups. It is notable that most visitors interviewed were foreigners and day-trippers, illustrating that Cape Town is an important tourist destination as indicated in the literature. The prominence of foreigners and day-trippers correlated with higher income and educational levels among visitors which is aligned to the profiles of travellers to tourism destinations generally. While population groups reflect the different races in South Africa, the disproportionate prominence of Whites is evident and again reflects the socio-economic status of visitors to CMT locations in Cape Town. The respondents in this study participated in a range of CMT activities and indicated an interest to participate in future activities. This suggests that there is a growing demand for CMT activities in Cape Town which needs to be managed. There is also high levels of satisfaction with CMT locations and experiences. This is reflected in the high levels of future interest to participate in CMT activities; the majority of the respondents stating that they would advise friends, relatives or colleagues to participate in CMT activities in Cape Town; and high positive ratings of perceptions of the CMT locations in relation to maintenance, signage, safety, facilities and infrastructure, entertainment opportunities and the promotion of responsible environmental practices.

It is important to undertake empirically-based assessments of CMT visitor profiles, preferences, perceptions and experiences in different locations in South Africa and globally. These studies will permit a comparative analysis in relation to different locations as well as over time to assess changes in trends and patterns. Additionally, more indepth analyses should assess how socio-demographic variables (such as gender, population group and income levels) influence preferences, perceptions and experiences. Furthermore, as indicated earlier, future research should unpack why CMT site visitors are interested in CMT activities but do not participate in these during specific visits to CMT locations. 


\section{Aknowledgments}

The research was funded by the NDT in South Africa as part of a broader project to develop a framework to assess the economic impacts of CMT in the country. The NDT and Expert Forum colleagues are thanked for their support and inputs.

\section{REFERENCES}

Atzori, R., Fyall, A., \& Miller, G. (2018). Tourist responses to climate change: Potential impacts and adaptation in Florida's coastal destinations. Tourism Management, 69: 12-22.

Biggs, D., Hicks, C., C., Cinner, J., E., \& Hall, C., M. (2015). Marine tourism in the face of global change: The resilience of enterprises to crises in Thailand and Australia. Ocean and Coastal Management, 105: 65-74.

Bob, U., Swart, K., Ngalawa, H., \& Nzimande, N. (2018). Methodological challenges in assessing the economic impacts of coastal and marine tourism in South Africa: Reflections from a piloting project. EuroEconomica, 1 (37): 202-217.

Brouwer, R., Hadzhiyska, D., Ioakeimidis, C., \& Ouderdorp, H. (2017). The social costs of marine litter along European coasts. Ocean and Coastal Management, 138: 38-49.

Carvache-Franco, W., Carvache-Franco, M., Carvache-Franco, O., \& Hernández-Lara, A., B. (2019). Segmentation of foreign tourist demand in a coastal marine destination: The case of Montañita, Ecuador. Ocean and Coastal Management, 167: 236-244.

Chen, C., L., \& Teng, N. (2016). Management priorities and carrying capacity at a high-use beach from tourists' perspectives: A way towards sustainable beach tourism. Marine Policy, 74: 213-219.

Frey, N., \& George, R. (2010). Responsible tourism management: The missing link between business owners' attitudes and behaviour in the Cape Town tourism industry. Tourism Management, 31 (5): 621-628.

Gallagher, A., J., \& Hammerschlag, N. (2011). Global shark currency: The distribution, frequency, and economic value of shark ecotourism. Current Issues in Tourism, 14 (8): 797-812.

Han, Y., Wei, F., Ye, G., Yang, S., Ma, P., \& Hu, W. (2018). A study on the evaluation the marine carrying capacity in Guangxi Province, China. Marine Policy, 91: 66-74.

Hattingh, C., \& Swart, K. (2016). The motives for visitors to attend a food and wine event in Cape Town and their satisfaction levels. African Journal of Hospitality, Tourism and Leisure, 5 (2): 1-14.

Higham, J., E., Bejder, L., Allen, S. J., Corkeron, P. J. \& Lusseau, D. 2016. Managing whale-watching as a nonlethal consumptive activity. Journal of Sustainable Tourism, 24(1):73-90.

Honey, M., \& Krantz, D. (2007). Global Trends in Coastal Tourism. Centre on Ecotourism and Sustainable Development. Washington, Stanford University.

Hoyt, E. (2001). Whale Watching 2001: Worldwide tourism numbers, expenditures, and expanding socio-economic benefits. International Fund for Animal Welfare, Yarmouth Port.

Hung, K., \& Petrick, J. F., (2011). Why do you cruise? Exploring the motivations for taking cruise holidays, and the construction of a cruising motivation scale. Tourism Management, 32 (2): 386-393.

Islam, M.M., \& Shamsuddoha, M., (2018) Coastal and marine conservation strategy for Bangladesh in the context of achieving blue growth and sustainable development goals (SDGs). Environmental Science and Policy, 87: 45-54.

Jarvis, D., Stoeckl, N., \& Liu, H., B., (2016). The impact of economic, social and environmental factors on trip satisfaction and the likelihood of visitors returning. Tourism Management, 52: 1-18.

Joseph, P., D. (2017). Sustainable Coastal Tourism Model. Atna-Journal of Tourism Studies, 12(1): 46-61.

Lithgow, D., Martínez, M.L., Gallego-Fernández, J.B., Silva, R., \& Ramírez-Vargas, D.L., (2019). Exploring the co-occurrence between coastal squeeze and coastal tourism in a changing climate and its consequences. Tourism Management, 74: 43-54.

Lucrezi, S., Geldenhuys, L., L., van der Merwe, P., \& Saayman, M. (2018). Utility of users data and their support for differential beach management in South Africa. In Beach Management Tools - Concepts, Methodologies and Case Studies (pp. 933-960). Springer, Cham.

Lucrezi, S., Saayman, M., \& van der Merwe, P. (2016). An assessment tool for sandy beaches: A case study for integrating beach description, human dimension, and economic factors to identify priority management issues. Ocean and Coastal Management, 121: 1-22.

Lucrezi, S., \& van der Walt, M., F. (2016). Beachgoers' perceptions of sandy beach conditions: Demographic and attitudinal influences, and the implications for beach ecosystem management. Journal of Coastal Conservation, 20(1): 81-96.

Liu, J., Liu, N., Zhang, Y., Qu, Z., \& Yu, J. (2019). Evaluation of the non-use value of beach tourism resources: A case study of Qingdao coastal scenic area, China. Ocean and Coastal Management, 168: 63-71.

Martinis, A., Kabassi, K., Karris, G., \& Minotou, C. (2019). Unveiling the profile of tourists in islands with protected areas to promote sustainable tourism. In Smart Tourism as a Driver for Culture and Sustainability (pp. 261-274). Springer, Cham. 
Mitra, J., Wilson, C., Managi, S., Kler, P., Prayaga, P., \& Khanal, U. (2019). What determines whale watching tourists' expenditure? A study from Hervey Bay, Australia. Tourism Economics, p.1354816619832789.

Myeza, J., Mason, R., B., \& Peddemors, V., M. (2010). Socio-economic implications of the KwaZulu-Natal sardine run for local indigenous communities. African Journal of Marine Science, 32 (2): 399-404.

Nulty, P., M., Annett, J., Balnaves, A., Joyce, J., \& Teyssedea, S. (2007). A strategy and action plan for the development of marine tourism and leisure in Lough Foyle and Carlingford Laughareas.(Prepared for: The Laughs Agency East Border Region Committee, North West Region Cross Border Group.

O’Connor, S., Campbell, R., Cortez, H., \& Knowles, T. (2009). Whale watching worldwide: Tourism numbers, expenditures and expanding economic benefits, A special report from the International Fund for Animal Welfare. http://www.ecolarge.com/wp-content/uploads/2010/o6/WWWWo9.pdf.

O’Malley, M., P., Lee-Brooks, K., \& Medd, H., B. (2013). The global economic impact of Manta Ray watching tourism.https://www.researchgate.net/publication/237061210_The_Global_Economic_Impact_ofMan ta_Ray_Watching_Tourism.

Oh, C., Draper, J., \& Dixon, A., W. (2010). Comparing resident and tourist preferences for public beach access and related amenities. Ocean and Coastal Management, 53 (Issues 5-6): 245-251.

Oladele, A.H., Digun-Aweto, O., \& Van Der Merwe, P., (2018). Potential of coastal and marine tourism in Nigeria. Tourism in Marine Environments, 13 (2): 165-173.

Onofri, L., \& Nunes, P., A. (2013). Beach 'lovers' and 'greens': A worldwide empirical analysis of coastal tourism. Ecological Economics, 88: 49-56.

Orams, M., B., \& Lück, M. (2014). Coastal and marine tourism. The Wiley Blackwell Companion to Tourism, pp. 479-489. Wiley: UK.

Orams, M., B., \& Page, S., J. (2000). Designing self-reply questionnaires to survey tourists: Issues and guidelines for Researchers. Anatolia, 11 (12): 125-139.

Rodella, I., Madau, F., Mazzanti, M., Corbau, C., Carboni, D., Utizi, K., \& Simeoni, U. (2019). Willingness to pay for management and preservation of natural, semi-urban and urban beaches in Italy. Ocean and Coastal Management, 172: 93-10.

Rogerson, C.M., \& Rogerson, J.M., (2019). Emergent planning for South Africa's blue economy. Urbani Izziv, 30 : 24-36.

Saayman, M., \& Saayman, A. (2017). How important are Blue Flag awards in beach choice? Journal of Coastal Research, 33 (6): 1436-1447.

Seymour, K. (2012). The perceived value of scuba diving tourists at a marine destination. Unpublished magister atrium thesis, North-West University, Potchefstroom.

Shelembe, S. (2015). SA's ocean to boost economy. https://www.vukuzenzele.gov.za/sa\%E2\%80\%99s-oceanboost-economy.

Tkaczynski, A., \& Rundle-Thiele, S. (2018). Identifying whale-watching tourist differences to maximize return on investment. Journal of Vacation Marketing, p.1356766718814083.

Trave, C., Brunnschweiler, J., Sheaves, M., Diedrich, A., \& Barnett, A. (2017). Are we killing them with kindness? Evaluation of sustainable marine wildlife tourism. Biological Conservation, 209: 211-222.

Vianna, G., M., S., Meekan, M., G., Pannell, D., J., Marsh, S., P., \& Meeuwig, J., J. (2012). Socio-economic value and community benefits from shark-diving tourism in Palau: A sustainable use of reef shark populations. Biological Conservation, 145 (1): 267-277.

*** DPME. (2014). Operation Phakisa - Oceans Economy: Coastal and Marine Tourism. http://www. operationphakisa.gov.za/Pages/Home.aspx.

*** DPME. (2015). Maritime Cluster - Operation Phakisa Ocean Economy: Coastal and Marine Tourism. http://maritimecluster.co.za/phocadownloadpap/Cruise\%2oTourism\%2oSummit.pdf.

*** Maritime Cluster. (2015). Operation Phakisa Ocean Economy: Coastal and Marine Tourism. http://maritime cluster.co.za/phocadownloadpap/Cruise\%20Tourism\%20Summit.pdf.

*** Mediterranean Maritime Integrated Projects. 2014. Coastal and Maritime Tourism. http://www.medmaritimeprojects. eu/download/ProjeCMTediamer/SH_Meeting_WME/WM_Tourism_factsheet_300115. pdf [15 December 2016].

*** NDT. (2016). Coastal and marine tourism: Stakeholder engagement and sign off. Unpublished document.

*** New Zealand Tourism Research Institute. (2009). Marine tourism, fisheries and community: Creating barometers of economic change. http://www.nztri.org/node/285.

*** Operation Phakisa. (2014). Oceans Economy: Coastal and Marine Tourism. http://www.operationphakisa. gov.za/Pages/Home.aspx.

*** Statistics South Africa. (2015). Tourism and migration. http://www.statssa.gov.za/publications/Po351/ P0351March2015.pdf.

*** UN. (2014). The oceans economy: Opportunities and challenges for small developing island developing states. http://unctad.org/en/PublicationsLibrary/ditcted2014d5_en.pdf.

*** UNEP. (2009). Sustainable coastal tourism: An integrated planning and management approach. http://www.unep.org/pdf/DTIE_PDFS/DTIx1091xPA-SustainableCoastalTourism-Planning.pdf.

Submitted:

26.07.2019
Revised:

02.12.2019
Accepted and published online

04.12.2019 